\title{
Classification and Efficiency Analysis of Slovenian Restaurant SMEs
}

\author{
Tanja Planinc \\ University of Primorska, Slovenia \\ tanja.planinc@fts.upr.si \\ Marko Kukanja \\ University of Primorska, Slovenia \\ marko.kukanja@fts.upr.si \\ Saša Planinc \\ University of Primorska, Slovenia \\ sasa.planinc@fts.upr.si
}

Focusing on the characteristics of restaurant SMES, the purpose of this paper is to use (1) a cluster analysis (CA), and (2) data envelopment analysis (DEA) approach to classify restaurant SMES into different groups based on their physical and managerial characteristics and attempts to determine whether differences exist in the efficiency performance of different groups. The study has conducted a two-step ca and DEA analysis to identify the effects of restaurant characteristics on efficiency performance. This method takes into consideration the presence of heterogeneous subsets in efficiency assessment. Restaurants were preselected based on their operational characteristics. SMES whose only source of income was their restaurant business were included in the study. Surveys were performed with restaurant managers, and the firms' financial reports were analysed. Two diverse groups were identified: smaller restaurants with younger and less experienced managers, and bigger restaurants with older and more experienced managers. The various physical (number of seats, years of business activity) and managerial (age, and professional experience) characteristics appeared to significantly affect restaurant types differently. Established restaurants with more seats, older and more experienced managers proved to be more efficient. This is the very first study to analyse Slovenian restaurant businesses efficiency with a combined CA-DEA approach. Primary data was collected by surveying restaurant managers while secondary financial data was provided by national tax authorities after the implementation of fiscal cash registers.

Keywords: cluster analysis, DEA, efficiency, restaurant industry, Slovenia, SMES

https://doi.org/10.26493/2335-4194.11.31-42

\section{Introduction}

This study analyses the productive efficiency of small and medium-sized (SME) restaurant businesses in Slovenia. Recently, a considerable body of literature has developed around the theme of efficiency mea- surement. The literature has extensively reviewed efficiency practices for the lodging industry (Assaf \& Agbola, 2014; Assaf \& Barros, 2013; Wu, Liang, \& Song, 2010), but there is less evidence from the restaurant sector (Reynolds \& Thompson, 2007; Roh \& 
Choi, 2010) and even less from restaurant smes (Assaf, Deery, \& Jago, 2011).

This research was performed in Slovenia, where restaurant SMES represent a significant part of the tourism sector within the national economy. Statistical and financial data show that tourism is one of the most important facets of the Slovene national economy. In 2016, tourism provided employment to $13 \%$ of all employees in the country and contributed $12.7 \%$ to the Slovenian Gross Domestic Product (GDP) (World Travel \& Tourism Council, 2018; http://pxweb.stat.si/ pxweb/Database/Economy/Economy.asp). The food and beverage ( $\mathrm{\&} \mathrm{B})$ service sector is a vital and integral element of tourism, and an essential economic activity (Kukanja, 2015). In 2016, there were 2,516 companies operating in the $\mathrm{F} \& \mathrm{~B}$ sector $(3.96 \%$ of all companies in Slovenia), employing a total of 8,988 people (2.08\% of all employees). The F \& B service sector represents a significant part of the Slovene national economy. Its performance has significant impacts and spill-over effects that go well beyond customers' needs for food and beverage. Specifically, the F\& B service sector has a multiplier effect on many economic activities and significantly boosts businesses that are losing their competitive advantage in the international marketplace (e.g., local food production). An essential subsector of the $\mathrm{F} \& \mathrm{~B}$ service sector is the restaurant sector, which includes almost $43 \%$ of all $\mathrm{F} \& \mathrm{~B}$ facilities in the country (see http://www.ajpes.si). According to official statistical classification of economic activities (the NACE classification) in the European Union $(\mathrm{EU})$, the restaurant sector is classified as $156.101-$ Restaurant and Inns. In this study, we focus on the efficiency analysis of the restaurant sector in Slovenia, which is by far the largest and the most important. This subsector is dominated by smes, with several industry-specific characteristics: the restaurants are mostly family-run businesses; on average, restaurants have 20 years of business activity; and the average number of employees is 8.7 per restaurant unit (Kukanja, 2015). Competition in this industry is severe and, as in other service industries, the restaurant industry is also highly sensitive to economic trends and changes in real household disposable income (Kosi \& Bojnec, 2013).
On the market, restaurant businesses are characterized by high levels of uncertainty and change (Kim, $\mathrm{Li}, \&$ Brymer, 2016). The industry is experiencing fast growth, globalisation pressure, high competitiveness, and international trends. Together, these aspects significantly add to current complexities and challenges in the industry. As noted by Parsa, van der Rest, Smith, Parsa, and Bujisic (2015), approximately $30 \%$ of all restaurant businesses in the UsA end up failing. Similarly, Lee, Hallak, and Sardeshmukh (2016a) reported that approximately three fifths of all restaurants in Australia earn an average net profit of just $2 \%$ after taxes, which makes the survival rates in the industry extremely low. Thus, understanding restaurants' efficiency performance is critical for the success of the restaurant and tourism sector, as well as for the livelihood of regions and countries depending on tourism income to survive. Consequently, the need for SMEs' managers and business owners to have a strong knowledge of operational, marketing and financial skills is arguably greater than ever before (Assaf et al. 2011). Management skills and knowledge are extremely important, as superior efficiency performance is strongly correlated with restaurant firms' superior financial performance (Kim et al., 2016). Due to the importance of the restaurant sector in the national economy, it is important for academics and practitioners to have more accurate information about restaurants' efficiency practices.

In previous studies (Reynolds \& Biel, 2007; Roh \& Choi, 2010), restaurant efficiency was mostly assessed based on managers' subjective feedback and simple ratio measures (e.g., input to output analysis). According to Assaf, Barros, and Josiassen (2012), conventional ratio approaches are limited, because they integrate too few operational characteristics to evaluate an overall operational efficiency. Efficiency measurement, in contrast, is based on the concept of a production possibility frontier (Barros, 2005) and econometric linear programming methods, such as DEA, which provides a useful diagnostic tool for analysing efficiency-based performance improvement at the individual unit level by simultaneously incorporating multiple inputs and outputs. DEA has proven to be an efficient internal benchmarking technique 
in the service industries. In hospitality research, several researchers have applied DEA to measure hotel efficiency (Alberca-Oliver, Rodríguez-Oromendía, \& Parte-Esteban, 2015; Barros, 2005; Sigala, Jones, Lockwood, \& Airey, 2005) and restaurant efficiency (Assaf et al., 2011; Fang \& Hsu, 2014; Reynolds \& Biel, 2007; Reynolds \& Thompson, 2007). Although DE A proved to be an effective tool for efficiency measurement, its major drawback is its inability to distinguish different decision making units (DMU) based on their operational characteristics. Therefore, this paper applies CA to increase the discriminatory power of DEA and to improve the classification of restaurants. First, restaurant businesses were divided into different groups based on their physical and managerial characteristics. Taking a post hoc approach to restaurant market classification, DEA was introduced to analyse restaurants' efficiency based on financial data officially provided by the national tax authorities. This study presents an alternative approach to efficiency measurement. No previous study classified restaurants according to their operational characteristics (CA) and efficiency performance (DEA). Applying CA-DEA methodology enables practitioners and researchers to better understand restaurants' efficiency based on their operational characteristics. Using this approach, this study presents an important insight into restaurant SMEs' efficiency performance. As noted by Lee, Hallak, \& Sardeshmukh (2016b), an academic approach to efficiency measurement is essential, as entrepreneurs often do not possess sufficient resources for a complex data and benchmarking analysis.

The present study is the first to explore restaurant SMEs' efficiency in Slovenia. The specific objectives of this study were as follows:

1. to determine differences between restaurant SMES based on their managerial characteristics and the restaurants' physical characteristics;

2. to measure the overall efficiency of restaurant SMES in Slovenia; and

3. to identify potential differences in efficiency performance between homogeneous clusters (groups) of restaurants.

The overall structure of the study takes the form of four sections, including this introduction. Section 2 begins by laying out the theoretical dimensions of the research. Section 3 is concerned with the methodology, research results, and findings. Finally, the conclusion presented in Section 4 gives summary and critique of the findings.

\section{Literature Review}

Traditional Approaches to Efficiency Measurement The term 'efficiency' in economic theory was broadly defined by Farrell (1957) as the maximum output from a given set of inputs. Based on his definition, service industries have historically utilized partial ratio analysis to analyse a firms' efficiency and to benchmark its performance with competitors (Coelli, 1995; Riley, 1999). Given the labour-intensiveness of tourismrelated businesses, interest in productivity has predominantly focused on labour and its corollaries (e.g., service outcome per employee). While useful for specific intrafirm analysis, these partial-factor statistics measures have limited utility, as they reflect only specific operational attributes. In terms of benchmarking analysis, these methods have some major drawbacks, as most partial-factor ratios fail to account for potentially meaningful differences among food-service operations. Therefore, the use of single input-to-output ratio measures should be treated with extreme interpretative caution (Joppe \& Li, 2016). According to Assaf and Matawie (2009), another potential problem is that many partial measures (single statistics) could be difficult to interpret if some indicators move in opposite directions over a given period. Nevertheless, Reynolds and Biel (2007) state that the use of simple ratio measures remains the most common practice to evaluate operational performance in the restaurant industry, although these measures have been proven to provide limited and inconsistent benchmarking information. The focus on efficiency measurement has evolved dramatically since the mid-199os. Building on Reynolds' (1998) definition of productivity as the effective use of resources to achieve operational goals, researchers and practitioners have acknowledged the importance of productivity measures that are more comprehensive than any single-factor indices. Donthu Hershberger \& Osmonbekov (2005) advocated the 
need for more rigorous methodological approaches (presented below) to handle multiple inputs and outputs simultaneously. Ideally, these methods would substantially mitigate shortcomings associated with traditional measurement techniques.

\section{Efficiency Frontier Approaches - DEA}

Efficiency is based on the concept of a production possibility frontier (Barros, 2005). The production possibility frontier represents the maximum output attainable from each input level. Productive efficiency, therefore, refers to whether internal resources in the production process were used efficiently to produce operational service capacity effectively (Huang, Ho, \& Chiu, 2014). With the knowledge of the frontier, one can estimate different components of productive efficiency - specifically, technical and allocative efficiency. The former reflects a firms' ability to obtain maximum outputs from a given set of inputs, whereas the latter reflects the ability to use the inputs in optimal proportions given their input prices. These two measures are then combined to provide a measure of total cost efficiency. Thus, if an organization is allocatively and technically efficient, it can be said to have achieved total cost efficiency. According to Assaf and Matawie (2009), the efficiency frontier analysis is described as an effective tool for identifying areas of cost containment and cost reduction. In scientific literature (Coelli, 1995; Reynolds, 2003; Reynolds \& Biel, 2007), different holistic analysis techniques for efficiency measurement have been proposed. The most common ones are DEA (presented below) and stochastic frontier analysis, or SFA (a complex parametric technique that requires function specification of the functional form).

While still residing in the output-to-input ratio measurement domain, DEA solves many of the problems associated with the aforementioned measures by integrating multiple outputs and inputs simultaneously, and it is especially useful for the analysis of firms that are characterized by multiple resources and multiple services. This approach allows for both controllable (discretionary) and uncontrollable (nondiscretionary) variables, producing a single relative-tobest productivity index that relates to all units under comparison. Mathematically, DEA is the ratio of the weighted sum of outputs to the weighted sum of inputs (Wei, 2001). On a more general basis, if the number of inputs and outputs is potentially infinite (this form of DEA is known as the ratio form), the weights estimated for one unit are such that, when they are applied to corresponding outputs and inputs in the analysis, the ratio of weighted outputs to weighted inputs is less than or equal to 1 . Since DE A seeks an optimization contingent on each separate unit performance (also referred to as the unit relative efficiency or productivity) in relation to the performance of all units, those with the greatest productivity have a score (P) of 1, suggesting $100 \%$ efficiency when compared with those in the competitive set. Finally, if a firm uses multiple inputs, defined by the point $\mathrm{P}$ (the isoquant of a fully efficient firm is 1) to produce a unit of output, the technical (in)efficiency ratio could be represented by the distance to the point $P=1$ value, which is the proportional reduction in all inputs that could be theoretically achieved without any reduction in the output(s).

\section{DEA in Restaurant Efficiency Studies}

DEA has been applied to several restaurant industry studies (Assaf et al., 2011; Banker \& Morey, 1986; Fang \& Hsu, 2014; Hruschka, 1986; Reynolds \& Biel, 2007; Reynolds \& Thompson, 2007). For example, Hruschka (1986) determined differences in efficiency among ten different restaurant groups, Banker and Morey (1986) analysed efficiency in a fast-food chain with 60 restaurants. Reynolds (2003) used DEA to evaluate the performance of a chain restaurant and suggested that the average efficiency score could be increased by as much as $22 \%$. Reynolds and Thompson (2007) further assessed the multiunit restaurant efficiency score for a chain of 62 full-service restaurants and found that their average efficiency level was $82 \%$. Reynolds and Biel (2007) analysed the efficiency score of 36 samebrand units of a casual theme restaurant chain in the USA. Authors found that only eight units were fully efficient, with the average efficiency score at $86 \%$. In their study, Roh and Choi (2010) assessed the efficiency of different brands within the same franchisor using DEA; the results indicated a low average effi- 
ciency $(73 \%)$ and showed that the efficiency of each establishment and brand differed significantly from the others. Similarly, Assaf et al. (2011) used DE A to assess the efficiency and return to scale of the 105 Australian restaurants. The results revealed a low level of efficiency (on average $46.17 \%$ ) and highlighted the critical impact of factors such as restaurant size and management experience on the efficiency results. A different approach was implemented by Taylor, Reynolds, \& Brown (2009) and Fang and Hsu (2014). These authors implemented DEA for multiple factor menu analysis to increase menu items' financial performance. In their study, Fang and Hsu (2014) also investigated differences between two frontiers using the metafrontier value for different dining periods as well as for the efficiency of different menu items. The results revealed that the efficiency of the metafrontier DEA method increased profitability by $15 \%$ compared with the traditional menu engineering method.

O'Donnell, Rao, and Battese (2008) further indicated that DEA might also produce inaccurate results if samples are considered in different environments (e.g., different dishes served during lunch and dinner, different chefs' proficiencies, etc.) and thus should not be treated as a homogeneous frontier. To account for this problem, Battese, Rao, and O'Donnell (2004) first introduced the technology-gap ratio; later, O'Donnell et al. (2008) introduced the metatechnology-gap ratio (MTR), which quantifies the efficiency of heterogeneous groups based on their distances from a common frontier. As production frontiers may change in different periods or even within a single unit analysis, the traditional (common) production frontier cannot be applied generally. Therefore O'Donnell et al. (2008) employed DEA to construct a metafrontier to DEA analysis (MDEA) by pooling all observations from all groups and by constructing various group frontiers to measure their efficiencies and MTRS relative to the metafrontier. The metafrontier DEA model is a complex academic model able to calculate the comparable efficiencies for firms operating under different technologies. However, on a daily basis, it provides little information of practical value for restaurant managers, and it does not facilitate restaurants' benchmarking process (Assaf \& Josiassen, 2016).

\section{CA in Restaurant Studies}

CA has long been used as a preliminary method for market segmentation (clustering). Traditionally, researchers' segment market groups a priori: first selecting a defining variable, then segmenting based on this specific variable. Characteristics of the segments are then described based on the specifics of this original descriptor variable (e.g., lifestyle, demographic, geographic measures etc.), as well as other distinguishing attributes. Often consumers are grouped by age, gender, service preferences or purpose (Yüksel \& Yüksel, 2003). While these descriptive methods provide useful data, they cannot reveal objective patterns or imply causation. Therefore, scholars (Mooi \& Sarstedt, 2011) call for the industry to implement multivariate statistical techniques instead of traditional descriptive methods to gain a better understanding of market segments. One of these multivariate methods is $\mathrm{CA}$, which is commonly used in tourism (mostly hotel and travel) and marketing research to segment market groups.

In terms of restaurant industry research, only few studies have used this technique for segmenting restaurant guests (Carlson, Kinsey, \& Nadav, 2002; Gursoy, McCleary, \& Lepsito, 2003; Swinyard \& Struman, 1986; Yüksel \& Yüksel, 2003) and managers (Marzuki, Hall, \& Ballantine, 2014). As Duncan, Josiam, Kim, and Kalldin (2015, p. 1381) point out: 'Since 2000 the CA has increased in popularity but is still infrequently used in the academic literature pertaining to the restaurant industry to divide customers into distinct market segments.'

To date, no research has been found that measured restaurant efficiency pre-based on $\mathrm{CA}$, although this approach has been widely used in other service industries, such as hotels (Denizci Guillet, Guo, \& Law, 2015), banks (Dharmapala \& Edirisuriya, 2011), and logistics (Marchetti \& Wanke, 2017).

\section{Research Methodology}

Instrument Development and Variable Identification

A questionnaire was developed for this research. It comprised over 25 items and was grouped into two major areas: general information about respondent (manager) and restaurant facility. General informa- 
tion items (primary data) derived from previous studies (Fang \& Hsu, 2014; Kukanja \& Planinc, 2013; Reynolds \& Taylor, 2011) and were used for classification purposes in the CA analysis (see Table 2). In the next step, financial variables (secondary data) for restaurants efficiency assessment (DEA) were identified.

According to Reynolds (2004), the application of DEA to the restaurant industry is particularly advantageous because the method accommodates both controllable input variables (those within managers' purview; e.g., labour hours, cost of goods, employee satisfaction, etc.) and uncontrollable input variables (environmental factors; e.g., number of competitors, parking capacity, number of seats, rent and taxes, location, etc.). Similarly, the selection of output variables enables the inclusion of several financial (e.g., operating revenue, gross profit, etc.) and non-financial variables (e.g., guest satisfaction, restaurant popularity, etc.). According to Sigala (2003), the analysis process can include any number of input and output variables. While the number of potential variables is relatively limitless, the literature review suggests that some (e.g., revenue) are 'essential,' while others offer provocative possibilities. Reynolds (2003) and Reynolds and Thompson (2007) proposed the basic groups of variables that have proved to be important for restaurants' efficiency analysis: financial, physical, and composite (reflecting both financial and physical variables). Regarding outputs, the critical variables are revenue, profit, guest/employee satisfaction, and retention equity. Regarding inputs, financial measures that have proven to be significant include labour costs, cost of goods sold, controllable fixed expenses, and uncontrollable expenses. Physical inputs that have proven to be important include service capacity (square footage or number of seats) and environmental characteristics (e.g., competitive conditions) (Reynolds \& Taylor, 2011). According to Lynn (2001), the validity and usefulness of such a generalised approach to variable selection is somewhat problematic, as, due to lack of available and reliable information, researchers often base their studies on several assumptions. For example, Reynolds and Thompson (2007) used restaurant sales as a surrogate for profitability, since they did not have access to profitability data. Reynolds (2004) used charged tips as a surrogate measure of customer satisfaction; similarly, Reynolds and Thompson (2007) also assumed that paid gratuities serve as an adequate measure of customer satisfaction. According to Wöber (2007), all DEA variables must be thoroughly preselected in accordance with the availability of reliable data.

The major advantage of the present study is that it avoids the problem of assumptions (surrogates) and subjective self-reported primary data. In the present study, secondary financial data provided by the national tax authorities were used to assess restaurants efficiency. Prior to applying DEA, the authors of the present study ensured that each input was related to at least one output (see Table 1), as previously suggested by Reynolds (2003).

The analysis began with pre-selecting the financialbased input variables. To begin this process, all operating items included in the standardized profit and loss ( $\mathrm{P} \& \mathrm{~L})$ report were used as potential input variables. Based on the correlation analysis, only the following operational variables had positive correlations $(p<0.01)$ and were therefore suitable for the subsequent DEA application: F\&B cost of goods sold, cost of part-time employees, cost of full-time employees, and depreciation (see Table 1). Regarding output variables, only net sales revenues were included in the study. Specifically, a potentially negative financial output value in DEA (e.g., negative profit) might project this inefficient unit onto the efficient frontier as a radial expansion and make the mix of efficiency results even more negative.

The results of the correlational analysis clearly indicate that only five financial variables are suitable for efficiency measurement using DEA.

\section{Data Collection and Sample Description}

Given the research objectives, data were collected from 142 restaurant sms located throughout the country. Since the identification of a competitive set is crucial for a successful benchmarking process (Barrows, Vieira, \& DiPietro, 2015), the authors of the present study focused only on those restaurants that operate with comparable operational variables. This research is, therefore, predicated on the following precondi- 
Table 1 Correlation Coefficients between Input and Output Variables

\begin{tabular}{|c|c|c|c|c|c|}
\hline \multirow{2}{*}{\multicolumn{2}{|c|}{ Input }} & \multicolumn{4}{|c|}{ Output } \\
\hline & & Acquisition $\cos ^{\mathrm{a}}$ & Costs of services & Labour costs & Depreciation \\
\hline \multirow[t]{2}{*}{ Net sales revenues } & Pearson Correlation & $0.982^{\star *}$ & $0.918^{\star *}$ & $0.874^{\star *}$ & $0.871^{\star *}$ \\
\hline & Sig. (2-tailed) & $0.000^{* *}$ & $0.000^{* *}$ & $0.000^{\star *}$ & $0.000^{\star *}$ \\
\hline
\end{tabular}

Notes ${ }^{a}$ Of goods and material sold and costs of material. ${ }^{* *}$ Correlation is significant at the o.o1 level (2-tailed).

tions: SMES with similar physical characteristics officially classified as restaurants, inns, or snack facilities; independently run restaurant facilities (not part of a hotel or food chain); and the restaurant business is the only source of income in restaurant firms' financial statements. The last of these preconditions presented one of the major challenges to identifying appropriate sample firms. Specifically, restaurant firms often diversify their business activities, which are aggregated in common financial statements; restaurant firms are frequently officially registered for several business activities; seasonal facilities are commonly registered as full-time businesses; and closed facilities are not automatically deleted from the official business register. To ensure that all restaurant units included in the study matched the research criteria, randomly selected businesses $(n=850)$ were pre-checked by ten interviewers in a vast field research during the winter and spring of 2017. If the restaurant appeared to match the research criteria and the manager agreed to participate in the study, the manager was asked to complete the questionnaire by providing general information about himself and the restaurant. The final analysis is, therefore, based on 137 independently operated restaurants located throughout the country (five restaurants were excluded from further analysis due to incomplete data).

In the next step, restaurant firms' annual financial reports (balance sheets and income statements), which are in the public domain under Slovene legislation, were thoroughly analysed. The authors of this study focused on the 2016 fiscal year. Namely, in 2016 fiscal cash registers (also referred to as fiscal memory devices are electronic devices used for registering and controlling tax revenuesat a point of sale) were implemented. Therefore, it can be assumed that the official financial data represented a solid base for reliable efficiency analysis.

\section{Analysis and Findings}

In the first step, descriptive statistics were used to analyse respondents' demographics and restaurants' physical characteristics $(n=137)$. Most respondents were slightly less than 45 years of age on average, and the sample was composed of a majority of male managers $(60.1 \%)$. The highest number of managers had completed secondary (vocational) education (70.9\%); $26.4 \%$ of managers had acquired a high school education; $2 \%$ had finished elementary school; and $0.7 \%$ of managers had obtained a master's degree. On average, managers had 21 years of experience in the industry. In addition to demographic data, restaurant characteristics were also analysed. Results show that most restaurants (41.1\%) employed from six to ten employees, followed by restaurants employing two to five employees (31.5\%), while only four restaurants (2.7\%) employed more than 20 workers. On average, the restaurants had less than 20 years of business activity (19.9 years), coinciding with managers' (owners') average years of experience (21 years). Following Reynolds (2004), managers were asked to indicate the number of competitors within a $1 \mathrm{~km}$ radius.

Results reveal a relatively uniform distribution of responses regarding the number of competitors. Most managers $(28.4 \%)$ indicated one to two competitors, $18.2 \%$ of managers identified no competition, and $17.6 \%$ of managers identified more than seven competitors within $1 \mathrm{~km}$ radius.

A CA was applied to classify restaurants into mutually exclusive groups (physical and managerial variables). CA was conducted using spss 24. The two step CA was used, since it can automatically determine the optimal number of clusters. This method is conducted in two steps. Formation of original cases into pre-clusters is the first step, followed by the second step, in which the standard hierarchical clustering algorithm is used. In the second step, the pre-clusters 
are combined into optimal number of clusters (Liew, 2013). In addition, with this method, data transformation is not required. The log-likelihood measure was used to reveal natural clusters. Schwarz's Bayesian information criterion was used to determine the optimal number of clusters. A drawback of this method is that missing values are not allowed and, therefore, cases with missing values are not included in the analysis (Ів м Knowledge Center, 2013).

A two-cluster solution (see Table 2) was identified based on the following variables: managers' age; managers' years of experience; years of restaurant operation; and number of seats. The two clusters are comparable by their size (cluster $1=68$ restaurants; cluster $2=69$ restaurants). To provide additional distinctive information about the two clusters and to confirm significant differences between variables in each cluster, an independent-samples T test was performed. As shown in Table 2, there were statistically significant differences between variables in both clusters.

- Cluster 1: Smaller - Younger and Less Experienced. As shown in Table 2, restaurants in this cluster ( $n$ $=68$ ) had fewer seats ( 98 seats) and fewer years of business operation (11.8 years). In contrast with the other cluster, managers of this cluster were much younger (37.97 years) and with less professional experiences (15.02 years). Therefore, this cluster was designated as 'smaller - younger and less experienced.'

- Cluster 2: Bigger - Older and More Experienced. Compared with the other cluster, this cluster ( $n$ $=69$ ) was characterized by bigger sitting capacity (146.91 seats), and older (52.19 years) and much more experienced managers ( 29.46 years). In accordance with its dominant characteristics, this cluster was named 'bigger - older and more experienced.'

The results of CA clearly indicate that restaurant sMEs can be classified in two distinctive groups based on managerial and physical characteristics.

In the next step, DEA was performed using DEAP Version 2.1 software. The input-oriented DEA model, which measures a unit's ability to convert inputs to outputs, was employed, as suggested by Reynolds and
Biel (2007). Radial efficiency measures were taken using the DEA-CCR model. This model provides an objective method to structure various measures into a single (aggregate) meaningful performance score of technical efficiency (Roh \& Choi, 2010), which leads to the unit-efficiency scores described in the following section. The CCR model presumes constant returns to scale (CRS), which means that an increase in inputs results in a proportionate increase in the output levels. Seiford (1996) referred to this practice as 'relative efficiency', since a unit's variables are calculated to maximize the efficiency ratio, followed by comparing them to similar ratios of the best performing units.

Building on the correlation results from Table 1 , the final set of variables included four input variables and one output variable. Following Fang and Hsu (2014), a fixed selection of input variables was chosen. The selected financial variables present key input elements (also referred to as requisite assets) of any restaurant production process (labour, direct materials, production assets). The items in the preceding parentheses are expressed in financial terms as labour cost, cost of goods sold, and depreciation, respectively. Most restaurants are privately owned; therefore, their managers do not have to pay rent. As the restaurant business is the managers' only source of income, net sales revenues were used as an output variable to complete DEA.

First, the efficiency for the overall sample was analysed $(n=137)$. Results indicate that 21 of the units were efficient (showing scores of $100 \%$ ), with the average efficiency score at $85 \%$, which indicates that restaurants in the sample are $15 \%$ from achieving their maximum efficiency. The lowest-scoring restaurant had an efficiency score of 0.56 (or 56\%), while 54 restaurants were above the average efficiency score $(85 \%)$, and 62 restaurants were below the average efficiency score. The results also revealed that, in most restaurants, the cost of goods and cost of part-time employees are well-managed and provide little room for improvement. When analysing underperforming restaurants, it is evident that principal areas of potential efficiency enhancement are depreciation and labour costs. Comparing the two results, the underperforming restaurants could, on average, decrease their depreciation 
Table 2 Average Values of Variables in Both Clusters

\begin{tabular}{lrrr}
\hline Variable & Cluster 1 $(n=68)$ & Cluster 2 $(n=69)$ & t-values \\
\hline Age of the managers & 37.97 & 52.19 & $-12.357^{*}$ \\
Years of managers' experience in the industry & 15.02 & 29.46 & $-10.727^{*}$ \\
Years of restaurant operation & 11.80 & 29.60 & $-5.161^{*}$ \\
Number of seats in restaurant & 98.00 & 146.91 & $-3.954^{*}$ \\
\hline
\end{tabular}

Notes ${ }^{*} t$-values significant at the o.ooo level (2-tailed).

costs by more than $36 \%$ and their labour costs by more than $23 \%$ to achieve the same level of net sales revenues.

Next, efficiency was analysed within each cluster. The relative efficiencies of each subset demonstrated that the restaurants in Cluster 1 achieved an average efficiency score of $83 \%$, while restaurants in Cluster 2 achieved an average efficiency score of $87 \%$. The difference of efficiency achievement in both clusters was statistically significant $(p<0.05)$.

A possible explanation for these results might be that bigger restaurants performed better due to the economies of scale (measured as sitting capacity), which resulted in cost advantages due to their scale of operation. This conclusion is in line with previous results (Assaf et al., 2011). Another source of scale economies is the possibility of purchasing inputs at a lower per unit cost purchased in large quantities. These results are likely to be related to managers' years of experience. More experienced managers seem to better organise the production cycle in terms of efficiency management than their younger colleagues. As managers' years of experience seem to prevail, further long term studies that account for these variables will need to be undertaken.

According to Assaf et al. (2011), differences in methodologies and data used in different studies can interfere with the comparison of DEA efficiency results. Nevertheless, the efficiency scores identified in our study are mostly in line with the findings of previous studies. For example, Assaf et al. (2011) reported that Australian restaurants operate with an average efficiency score at $46.17 \%$, while Fang and Hsu (2014) identified the average scores of two same-franchise restaurants in the USA as $87 \%$ (lunch) and $89 \%$ (dinner). Similarly, Reynolds and Biel (2007) reported that the average efficiency score of corporate-owned, same- brand casual theme restaurants in USA was $86 \%$; in a similar study, Reynolds and Thompson (2007) identified the average score as $82 \%$. By analysing three brands' restaurants operating under the same franchisor in USA, Roh and Choi (2010) concluded that their average efficiency score is $73 \%$. The comparison of results reveals that restaurants in Slovenia are relatively successful (in terms of efficiency scores).

\section{Conclusion}

This article has addressed the issue of efficiency measurement for the Slovenian restaurant industry. Research results suggest that the average level of restaurant SMEs' efficiency in Slovenia is $85 \%$. These results suggest that a substantial reduction in cost could be obtained if managers were to improve their current performance practices. The second major finding was that both identified groups of restaurants operate with different average efficiency scores - 'Smaller - younger and less experienced' (83\%) and 'Bigger - older and more experienced'( $87 \%)$.

The analysis was based on the CA-DEA model, which allows the integration of multiple environmental variables in determining the relative efficiency of different market groups. The results of this study clearly support the effectiveness of such approach as different efficiency scores for both groups of restaurants were identified. The insight of this method paints a deeper image of efficiency measurement, allowing for scholars and practitioners to develop tailored plans for efficiency improvement of different restaurant groups.

The present time is highly challenging for the restaurant industry. Increased efficiency and appropriate management seem to be the prerequisites for longterm financial survival (Hua \& Lee, 2014). The fact that the industry is made up largely of smes poses major challenges in relation to increasing the overall effi- 
ciency of the restaurant industry. Previous attempts at restaurant industry assessment mainly focused on industry reports (Roh \& Choi, 2010) and managers' feedback (Reynolds, 2004). The current study is the first to introduce reliable and comparable financial indicators, providing a more comprehensive and comparable assessment of restaurants' efficiency.

The results of this study could benefit the industry in several ways. First, we have provided restaurant managers with an opportunity to assess their level of performance against other competitors and to re-evaluate their management practices relative to efficient producers. Second, accurate efficiency measurement can provide a significant competitive advantage (e.g., operational optimization, employee performance management, etc.). Third, results can also be compared to regional operators that operate in comparable market circumstances. In sum, these results should draw the attention of managers to the potential improvements in overall performance, in terms of both effective utilization of inputs and financial performance.

While provocative, this study has several limitations. Firstly, DEA is not stochastic in nature, which means it does not allow for an error structure. Secondly, as there is no general, industry-wide acceptable method regarding the inclusion of variables, we focused on financial indicators. However, the inclusion of other variables (e.g., guest satisfaction) might help us to establish more accuracy on this matter. The major limitation of this study is the limitation to one year of operational data. Therefore, the investigated relationships could differ from country to country (especially outside the $\mathrm{EU}$ ) due to industrial composition, industry regulations, and other factors.

What is now needed is a longitudinal, cross-national study with a substantially larger dataset. More research is needed to better understand the efficiency of restaurants, especially in terms of determining the best performing practices. A follow-up qualitative study (interviews with managers), as previously done by Hummel and Murphy (2011), could also provide additional information. Given the growing importance of both financial and non-financial disclosures, it is suggested that future studies incorporate a set of non- financial measures of performance (e.g., innovation; corporate social responsibility). Finally, performing a similar study on different service industries could significantly contribute to the existing body of research.

In terms of practical implications, these findings suggest several courses of action for restaurant managers. The identification of the importance of different variables for efficiency performance (established restaurants with more seats, and older and more experienced managers proved to be more efficient) and the identification of average efficiency ratios provides a starting point for managers to study the processes of their own businesses and to easily benchmark distinctive differences in comparison to other properties.

\section{References}

Alberca-Oliver, P., Rodríguez-Oromendía, A., \& Parte-Esteban, L. (2015). Measuring the efficiency of trade shows: A Spanish case study. Tourism Management, 47, 127-137.

Assaf, A. G., \& Agbola, F. W. (2014). Efficiency analysis of the Australian accommodation industry: A Bayesian output distance function. Journal of Hospitality \& Tourism Research, 38(1), 116-132.

Assaf, A. G., \& Barros, C. P. (2013). A global benchmarking of the hotel industry. Tourism Economics, 19(4), 811-821.

Assaf, A., Barros, C. P., \& Josiassen, A. (2012). Hotel efficiency: A bootstrapped metafrontier approach. International Journal of Hospitality Management, 31, 621-629.

Assaf, A. G., Deery, M., \& Jago, L. (2011). Evaluating the performance and scale characteristics of the australian restaurant industry. Journal of Hospitality \& Tourism Research, 35(4), 419-436.

Assaf, A. G., \& Josiassen, A. (2016). Frontier analysis: A stateof-the-art review and meta-analysis. Journal of Travel Research, 55(5), 612-627.

Assaf, A., \& Matawie, K. M. (2009). A two-stage approach to efficiency modeling: An application to the Australian hospital food production industry. Journal of Hospitality \& Tourism Research, 33(3), 284-304.

Banker, R. D., \& Morey, R. C. (1986). Efficiency analysis for exogenously fixed inputs and outputs. Operations Research, 34(4), 513-521.

Barros, C. P. (2005). Measuring efficiency in the hotel sector. Annals of Tourism Research, 32(2), 456-477.

Barrows, C. W., Vieira, E. T., \& DiPietro, R. B. (2015). Increasing the effectiveness of benchmarking in the restaurant industry. International Journal of Process Management and Benchmarking, 6(1), 79-111. 
Battese, G. E., Rao, D. S. P., \& O’Donnell, C. J. (2004). A metafrontier production function for estimation of technical efficiencies and technology gaps for firms operating under different technologies. Journal of Productivity Analysis, 21(1), 91-103.

Carlson, A., Kinsey, J., \& Nadav, C. (2002). Consumers' retail source of food: A cluster analysis. Family Economics and Nutrition Review, 14(2), 11.

Coelli, T. J. (1995). Recent developments in frontier modelling and efficiency measurement. Australian Journal of Agricultural Economics, 39(3), 219-245.

Denizci Guillet, B., Guo, Y., \& Law, R. (2015). Segmenting hotel customers based on rate fences through conjoint and cluster analysis. Journal of Travel \& Tourism Marketing, 32(7), 835-851.

Dharmapala, P. S., \& Edirisuriya, P. (2011). A decision model to predict profitability using revised Thompson-Thrall profit ratios in DE A with an application to South Asian banks. International Journal of Operational Research, 12(4), 407-429.

Donthu, N., Hershberger, E. K., \& Osmonbekov, T. (2005). Benchmarking marketing productivity using data envelopment analysis. Journal of Business Research, 58(11), 1474-1482.

Duncan, J. L., Josiam, B. M., Kim, Y. H., \& Kalldin, A. C. (2015). Using factor-cluster analysis to segment patrons of casual dining establishments in the United States. British Food Journal, 117(4), 1377-1398.

Fang, C.-Y., \& Hsu, F.-S. (2014). An efficiency-based metafrontier approach to menu analysis. Journal of Hospitality \& Tourism Research, 38(2), 199-221.

Farrell, M. J. (1957). The measurement of productive efficiency. Journal of the Royal Statistical Society, A, 120(3), 253-290.

Gursoy, D., McCleary, K. W. \& Lepsito, L. R. (2003). Segmenting dissatisfied restaurant customers based on their complaining response styles. Journal of Foodservice Business Research, 6(1), 25-44.

Hruschka, H. (1986). Ansätze der Effizienzmessung von Betrieben. Journal für Betriebswirtschaft, 36(2), 76-85.

Hua, N., \& Lee, S. (2014). Benchmarking firm capabilities for sustained financial performance in the us restaurant industry. International Journal of Hospitality Management, 36, 137-144.

Huang, C., Ho, F. N., \& Chiu, Y. (2014). Measurement of tourist hotels? Productive efficiency, occupancy, and catering service effectiveness using a modified two-stage DE A model in Taiwan. Omega, 48, 49-59.

Hummel, E., \& Murphy, K. S. (2011). Using service blueprint- ing to analyze restaurant service efficiency. Cornell Hospitality Quarterly, 52(3), 265-272.

г в м Knowledge Center. (2013). Missing values. Retrieved from https://www.ibm.com/support/knowledgecenter/ en/SSLVMB_22.0.o/com.ibm.spss.statistics.algorithms/ alg_twostep_missing.htm

Joppe, M., \& Li, X. P. (2016). Productivity measurement in tourism: The need for better tools. Journal of Travel Research, 55(2), 139-149.

Kim, W. G., Li, J., \& Brymer, R. A. (2016). The impact of social media reviews on restaurant performance: The moderating role of excellence certificate. International Journal of Hospitality Management, 55, 41-51.

Kosi, T., \& Bojnec, ک̌. (2013). Institutional barriers to business entry in advanced economies. Journal of Business Economics and Management, 14(2), 317-329.

Kukanja, M. (2015). Restaurant quality measurement based on marketing factors - the managers' perspective. Academica Turistica, 8(2), 15-28.

Kukanja, M., \& Planinc, T. (2013). The response of the restaurant industry to the financial crisis. Ekonomska misao praksa, 22(1), 39-56.

Lee, C., Hallak, R., \& Sardeshmukh, S. R. (2016a). Drivers of success in independent restaurants. Journal of Hospitality and Tourism Management, 29, 99-111.

Lee, C., Hallak, R., \& Sardeshmukh, S. R. (2016b). Innovation, entrepreneurship, and restaurant performance: A higher-order structural model. Tourism Management, 53, 215-228.

Liew, H. (2013). Teach yourself cluster analysis, conjoint anal$y$ sis, and econometrics techniques. N.p.: Author.

Lynn, M. (2001). Restaurant tipping and service quality: A tenuous relationship. Cornell Hotel and Restaurant Administration Quarterly, 42(1), 14-20.

Marchetti, D., \& Wanke, P. (2017). Brazil's rail freight transport: Efficiency analysis using two-stage DEA and cluster-driven public policies. Socio-Economic Planning Sciences, 59, 26-42.

Marzuki, S. Z. S., Hall, C. M., \& Ballantine, P. W. (2014). Measurement of restaurant manager expectations toward halal certification using factor and cluster analysis. Procedia: Social and Behavioral Sciences, 121, 291-303.

Mooi, E., \& Sarstedt, M. (2011). A concise guide to market research: The process, data, and methods using IBM SPSS statistics. London, England: Springer.

O’Donnell, C. J., Rao, D. S. P., \& Battese, G. E. (2008). Metafrontier frameworks for the study of firm-level efficiencies and technology ratios. Empirical Economics, 34(2), 231-255. 
Parsa, H. G., van der Rest, J.-P. I., Smith, S. R., Parsa, R. A., \& Bujisic, M. (2015). Why restaurants fail? Part 4: The relationship between restaurant failures and demographic factors. Cornell Hospitality Quarterly, 56(1), 80-90.

Reynolds, D. (1998). Productivity analysis: In the on-site food-service segment. Cornell Hotel and Restaurant Administration Quarterly, 39(3), 22-31.

Reynolds, D. (2003). Hospitality-productivity assessment: Using data-envelopment analysis. Cornell Hotel and Restaurant Administration Quarterly, 44(2), 130-137.

Reynolds, D. (2004). An exploratory investigation of multiunit restaurant productivity assessment using data envelopment analysis. Journal of Travel \& Tourism Marketing, 16(2-3), 19-26.

Reynolds, D., \& Biel, D. (2007). Incorporating satisfaction measures into a restaurant productivity index. International Journal of Hospitality Management, 26(2), 352-361.

Reynolds, D., \& Taylor, J. (2011). Validating a DEA-based menu analysis model using structural equation modeling. International Journal of Hospitality Management, $30(3), 584-587$.

Reynolds, D., \& Thompson, G. M. (2007). Multiunit restaurant productivity assessment using three-phase data envelopment analysis. International Journal of Hospitality Management, 26(1), 20-32.

Riley, M. (1999). Re-defining the debate on hospitality productivity. Tourism and Hospitality Research, 1(2), 182186.

Roh, E. Y., \& Choi, K. (2010). Efficiency comparison of multiple brands within the same franchise: Data envelopment analysis approach. International Journal of Hospitality Management, 29(1), 92-98.

Seiford, L. M. (1996). Data envelopment analysis: The evolution of the state of the art (1978-1995). Journal of Productivity Analysis, 7(2-3), 99-137.
Sigala, M. (2003). Developing and benchmarking internet marketing strategies in the hotel sector in Greece. Journal of Hospitality \& Tourism Research, 27(4), 375-401.

Sigala, M., Jones, P., Lockwood, A., \& Airey, D. (2005). Productivity in hotels: A stepwise data envelopment analysis of hotels' rooms division processes. The Service Industries Journal, 25(1), 61-81.

Swinyard, W. R., \& Struman, K. D. (1986). Market segmentation: Finding the heart of your restaurant's market. Cornell Hotel and Restaurant Administration Quarterly, 27(1), 88-96.

Taylor, J., Reynolds, D., \& Brown, D. M. (2009). Multi-factor menu analysis using data envelopment analysis. International Journal of Contemporary Hospitality Management, 21(2), 213-225.

Wei, Q. (2001). Data envelopment analysis. Chinese Science Bulletin, 46(16), 1321-1332.

Wöber, K. W. (2007). Data envelopment analysis. Journal of Travel \& Tourism Marketing, 21(4), 91-108.

World Travel \& Tourism Council. (2018). Travel \& tourism economic impact 2017: Slovenia. London, England: Author.

Wu, J., Liang, L., \& Song, H. (2010). Measuring hotel performance using the integer DEA model. Tourism Economics, $16(4), 867-882$.

Yüksel, A., \& Yüksel, F. (2003). Measurement of tourist satisfaction with restaurant services: A segment-based approach. Journal of Vacation Marketing, 9(1), 52-68.

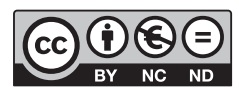

This paper is published under the terms of the Attribution- NonCommercial-NoDerivatives 4.0 International (CC B Y-NC-ND 4.0) License. 